\title{
A climate model inter-comparison of last interglacial
} peak warmth

\author{
Emma J. Stone ${ }^{1}$, P. Bakker ${ }^{2}$, S. Charbit ${ }^{3}$, S.P. Ritz and V. Varma ${ }^{5}$ \\ School of Geographical Sciences, University of Bristol, UK; emma.j.stone@bristol.ac.uk \\ Earth \& Climate Cluster, Department of Earth Sciences, Vrije Universiteit Amsterdam, The Netherlands; ${ }^{2}$ Laboratoire des Sciences du Climat et \\ de I'Environnement, CEA Saclay, Gif-sur-Yvette, France; ${ }^{4} \mathrm{Climate}$ and Environmental Physics, Physics Institute and Oeschger Centre for Climate \\ Change Research, University of Bern, Switzerland; ${ }^{5}$ Center for Marine Environmental Sciences and Faculty of Geosciences, University of Bremen, \\ Germany
}

A last interglacial transient climate model inter-comparison indicates regional and inter-model differences in
timing and magnitude of peak warmth. This study reveals the importance of different climate feedbacks and
the need for accurate paleodata in terms of age, magnitude and seasonality to constrain model temperatures.

Daleorecords and climate modeling studies indicate that Arctic summers were warmer during the last interglacial (LIG, ca. 130 to 115 ka BP) and global sea level was at least $6 \mathrm{~m}$ higher than today (Dutton and Lambeck 2012; Kopp et al. 2009), implying a reduction in the size of the Greenland and Antarctic ice sheets (Siddall et al. this issue). Previous snapshot climate model simulations for the LIG have shown summer Arctic warming of up to $5^{\circ} \mathrm{C}$ compared with the present day (Kaspar et al. 2005; Montoya et al. 2000), with the largest warming in Eurasia and the Greenland region. The LIG period provides an opportunity to test the current suite of climate models of varying degrees of complexity, under forcings that result in a warmer than present climate. To date, however, there has been no standardized inter-comparison of LIG climate model simulations.

Five European modeling groups (forming part of the Past4Future project) have performed experiments in order to characterize the response of the climate system to LIG changes in various climate forcings and biophysical feedback processes. These forcings and feedbacks include greenhouse gas concentrations (GHG), orbital configuration (ORB), vegetation feedbacks (VEG), and changes in ice sheet geometry (ICE). A key aim of this inter-comparison is to perform a number of sensitivity studies (e.g. ORB only, ORB+GHG, $\mathrm{ORB}+\mathrm{GHG}+\mathrm{VEG}, \mathrm{ORB}+\mathrm{GHG}+\mathrm{ICE}$ ) to ascertain the relative importance of the forcings and feedbacks in determining the trends and variability of LIG climate.

The Past4Future project has enabled the first long (> $10 \mathrm{ka}$ ) transient standardized inter-comparison for the LIG to be realized. These simulations consist of a range of model complexity with various forcings and feedbacks included: one full general circulation model CCSM3 (ORB; Collins et al. 2006; Yeager et al. 2006), one low-resolution general circulation model, FAMOUS (ORB+GHG; Smith 2012; Smith et al. 2008), and three Earth System Models of Intermediate Complexity: 1) CLIMBER-2 (ORB+GHG; Petoukhov et al. 2000), 2) Bern3D (ORB+GHG+ICE; Müller et al. 2006;

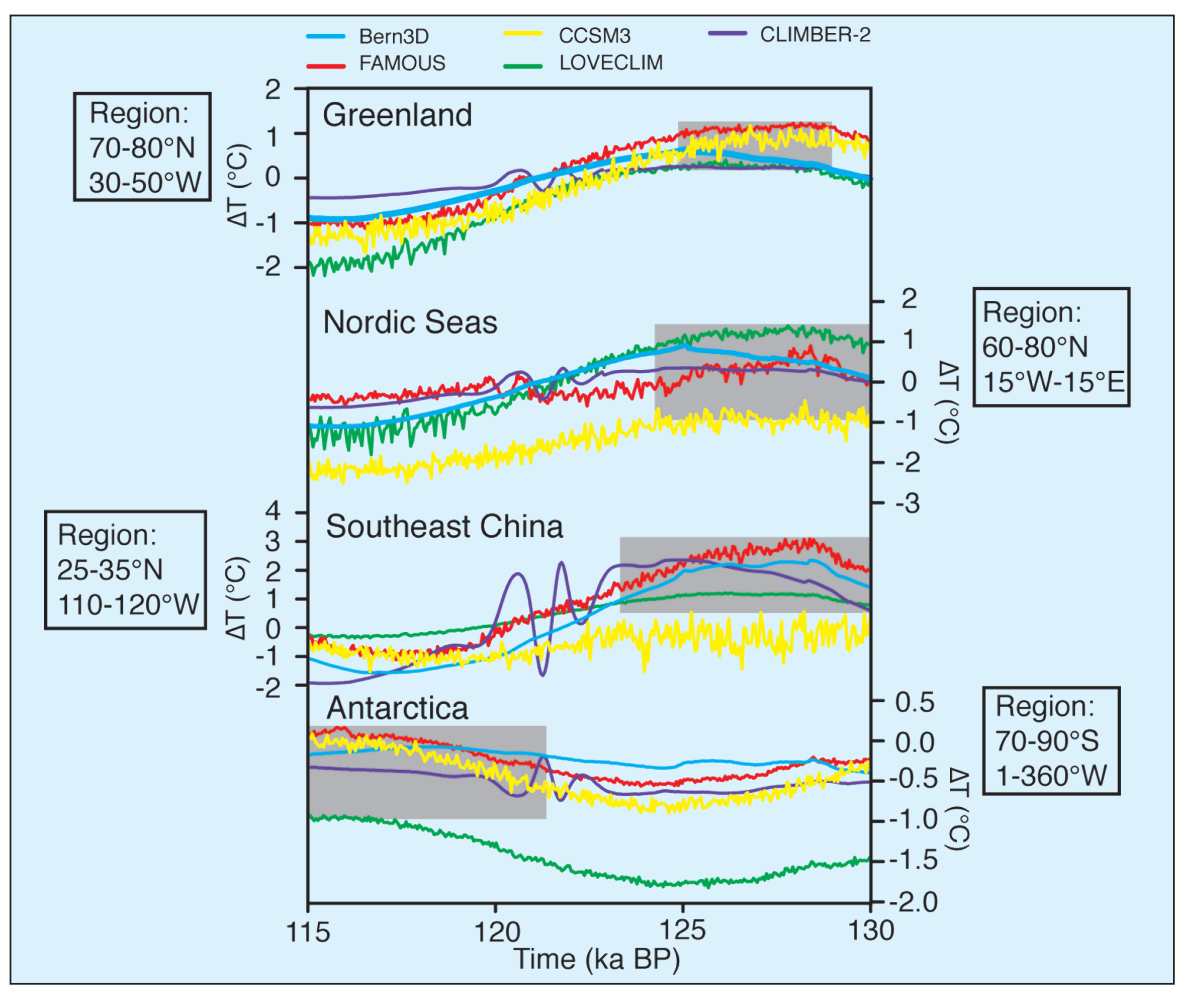

Figure 1: Summer 50-year global mean temperature anomalies spanning the LIG (ca. 130 to $115 \mathrm{ka} B P$ ) for five climate models of varying complexity. Note that these anomalies are calculated with respect to a preindustrial equilibrium climate representative of 1850 AD. For more details with respect to model setups and forcings see Bakker et al. (2012). The range in timing of the peak interglacial warmth is indicated by the gray bars.

Ritz et al. 2011), and 3) LOVECLIM (ORB+GHG; Goosse et al. 2010). CLIMBER-2, Bern3D, FAMOUS, and LOVECLIM use GHG and orbital forcings that conform closely to a set of standards described by the Paleo-modeling Intercomparison Project (PMIP3) while CCSM3 uses the same orbital configuration but with greenhouse gas values fixed according to mean LIG values. Bern3D is the only model that prescribes ice-sheet changes (and an associated freshwater forcing) by including the effect of remnant Northern Hemisphere ice sheets from the penultimate glaciation (all other models use present day ice sheet geometry).

One of the difficulties in understanding the response of the climate to LIG forcings is the lack of consensus in the paleodata on the timing of peak interglacial warmth in different regions of the Earth (e.g. The Nordic Seas and North Atlantic; Govin et al. 2012; Van Nieuwenhove et al. 2011). The interpretation of temperature signals of different resolution and seasonality obtained from paleoclimatic archives is also contentious (Jones and Mann 2004). Our climate modeling approach aims to inform on the spatial and temporal differences in peak warmth observed in the data, as well as on assessing the robustness of our climate model results (Bakker et al. 2013). Through this task it is also possible to gain an understanding of the climate feedbacks (e.g. changes in ocean overturning circulation and sea-ice) that are at play resulting from changed GHG concentrations and astronomical forcing.

\section{How does LIG summer temperature response compare in four different regions of the Earth?}

Figure 1 shows the 50-year summer average surface air temperature anomalies over four defined regions of the globe where paleodata exist for the time period 130 to $115 \mathrm{ka}$ BP.These model results demonstrate not only the differences in the timing of peak summer warmth 
between regions but also discrepancies between the models themselves. Greenland shows peak summer warmth during the early LIG for all five models with positive temperature anomalies compared with pre-industrial values ranging from $\sim 0.1$ to $1^{\circ} \mathrm{C}$, albeit substantially smaller than the $+5^{\circ} \mathrm{C}$ anomaly obtained from ice core records (e.g. NorthGRIP Project members 2004). Future simulations, which include a reduced Greenland ice sheet, may reconcile this difference between models and data.

Simulated maximum summer temperature anomalies for the Nordic Seas (-1.0 to $1.0^{\circ} \mathrm{C}$ ) and southeast China $\left(\sim 0\right.$ to $\left.3^{\circ} \mathrm{C}\right)$, however, indicate a less robust result between the models in terms of timing and temperature change. We compare our model results with a recent data synthesis by Turney and Jones (2010) and show that no model produces a maximum summer temperature anomaly as large as that inferred from paleodata (up to $+9^{\circ} \mathrm{C}$ ) for the Nordic Seas. This discrepancy could be due to missing feedback processes in the model simulations (such as vegetation changes), misrepresentation of ocean circulation and a simplistic representation of sea ice dynamics. Furthermore, the discrepancy could be larger still because the Turney and Jones (2010) data synthesis has been interpreted as an annual rather than a summer temperature signal. We also note that the Bern3D model simulation, which includes remnant ice sheets from the previous glacial, shows a delay in peak LIG warmth for Greenland and the Nordic Seas compared with the other models indicating the importance of this feedback.

In contrast to Greenland, timing of summer peak warmth in the Southern Hemisphere shows a substantial delay, with peak summer values (from -1 to $0.1^{\circ} \mathrm{C}$ ) only being obtained after $120 \mathrm{ka}$ BP. This contradicts a recent paleodata study (Govin et al. 2012) suggesting Southern Hemisphere peak warmth actually preceded Northern Hemisphere warming during the early part of the LIG.

\section{Seasonal timing of LIG maximum warmth}

Figure 2 shows the spatial distribution of timing of maximum LIG warmth during January and July. Superimposed are the four regions described above and given in Figure 1. During Northern Hemisphere winter (January), there is large variability between models in the timing of maximum warmth ranging from ca. 119 to $128 \mathrm{ka}$ BP over Greenland and the Nordic Seas. We relate these discrepancies at high northern latitudes during winter to differences in sea-ice feedback mechanisms (Bakker et al. 2013). In contrast, Southern Hemisphere winter (July) temperatures over Antarctica show less variability in timing of peak winter warmth. The temperature anomalies reach a maximum

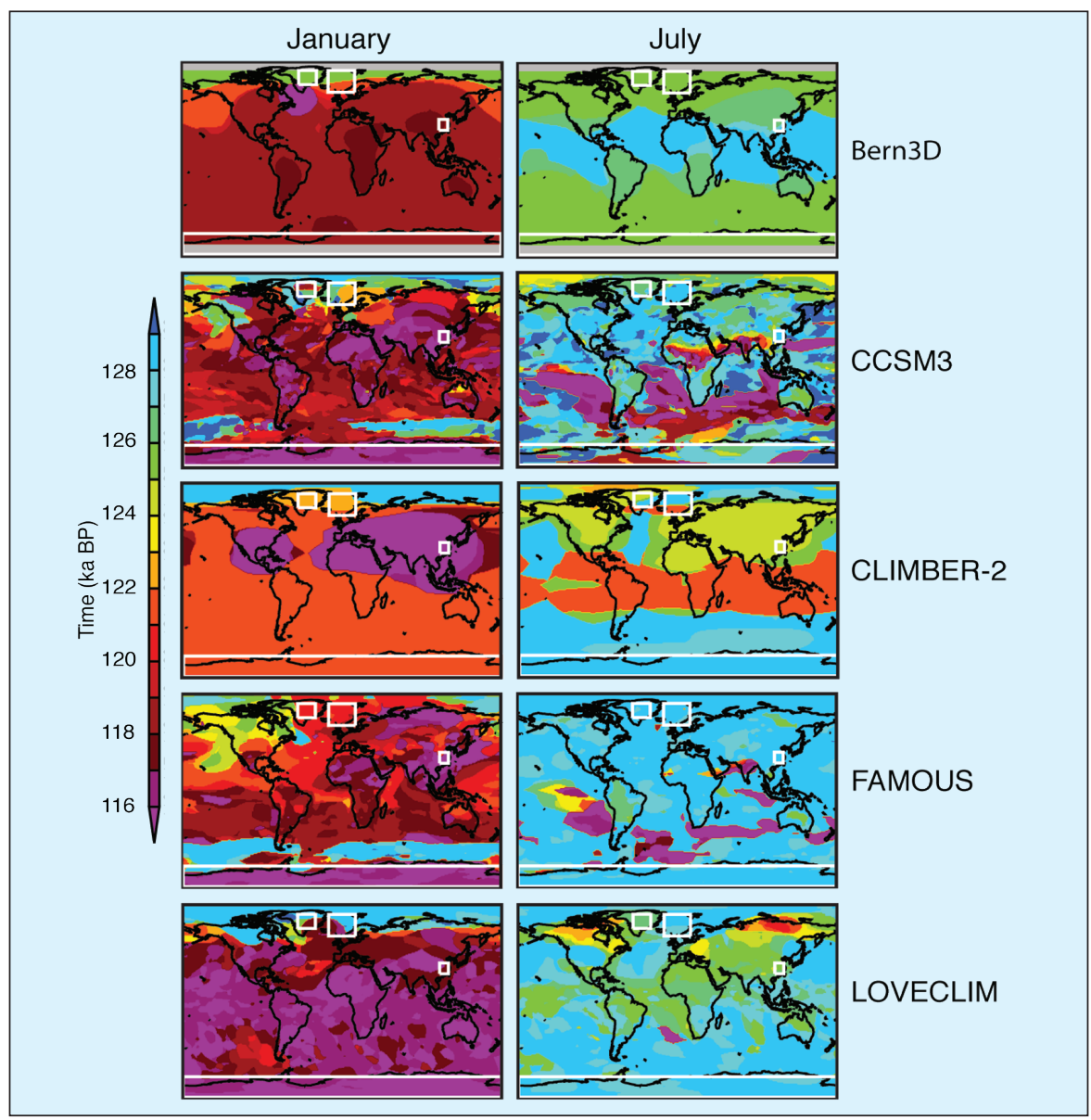

Figure 2: Timing of maximum LIG warmth for the months January and July for the five climate models of varying complexity. The regions defined in Figure 1 for Greenland, Nordic Seas, southeast China, and Antarctica are depicted by the white boxes. Figure modified from Bakker et al. (2013).

ca. 128 ka BP for CLIMBER-2, LOVECLIM and FAMOUS relating to those simulations which include the same forcings. There is a delay in peak warmth for Bern3D and CCSM3 (CCSM3 does not include transient GHGs and Bern3D includes remnant ice sheets and changes in freshwater forcing).

During the northern summer months, the inter-model comparison shows consistent timing of maximum warmth at high latitudes, ranging between ca. 124 and 128 ka BP (Fig. 2). This consistency is also the case for the Southern Hemisphere in July, but austral summer maximum warmth occurs much later (after 118 ka BP). In northern mid-to-low latitude regions, such as southeast China, all model simulations show reasonably similar results in timing of maximum warmth during the northern summer (July) and winter (January) months.

\section{Perspectives}

The Past4Future LIG modeling group provides important information for the data community regarding locations for relevant potential new paleoclimatic data. We also provide insights into understanding the mechanisms that result in differences in peak warmth timing and magnitude from proxy data temperatures around the world. Our results inform on the impact of remnant ice sheets and the importance of understanding the sensitivity of climate feedbacks during periods of enhanced warming. Part of the Past4Future data and modeling community remit is to reconstruct a coherent picture of LIG climate with the use of climate models to explain the temperature patterns observed in proxy observations. The next stage will be to take part in a detailed multi-millennial scale temperature comparison between model and data for the LIG. This will aim at understanding and explaining the differences between climate model results and how they might constrain future predictions of global warming.

\section{Selected references}

Full reference list online under:

http://www.pages-igbp.org/products/newsletters/ref2013_1.pdf

Bakker P et al. (2013) Climate of the Past 9: 605-619

Govin A et al. (2012) Climate of the Past 8: 483-507

NorthGRIP Project members (2004) Nature 431: 147-151

Turney CSM, Jones RT (2010) Journal of Quaternary Science 25: 839-843 Van Nieuwenhove N et al. (2011) Quaternary Science Reviews 30: $934-$ 946 